\title{
Thermal comfort in the low energy building - validation and modification of the Fanger model
}

\author{
Natalia Krawczyk ${ }^{1^{*}}$ \\ ${ }^{1}$ Faculty of Environmental, Geomatic and Energy Engineering, Kielce University of Technology, \\ 25-314 Kielce, Poland
}

\begin{abstract}
Nowadays, we spend most of our time inside buildings. Thus, ensuring adequate thermal comfort is an important issue. The paper discusses the issue of thermal comfort assessment in the intelligent low energy building "Energis" of Kielce University of Technology (Poland). The tests conducted in a selected lecture theater focused on collecting anonymous questionnaires containing thermal sensation and air quality votes of the respondents as well as performing measurements of indoor air parameters (air and globe temperatures, relative humidity, air velocity and $\mathrm{CO}_{2}$ concentration). Based on the obtained data a comparison has been done between the actual sensation votes of the volunteers and the calculation results performed with the Fanger thermal comfort model. Two indices have been considered in the paper: PMV (Predicted Mean Vote) and PPD (Predicted Percentage Dissatisfied). A modification of the model has also been proposed, which considers the impact of the carbon dioxide concentration on thermal comfort.
\end{abstract}

\section{Introduction}

The issue of thermal comfort is of increasing importance in the existing world. Nowadays, an increasing number of people spend their time indoors. This increases the interest in the conditions in a given room. More and more people are trying to ensure thermal comfort by using appropriate air-conditioning and heating devices. Proper thermal conditions are key elements for our well-being, health and productivity. Not providing the right conditions can adversely affect our immune system and we start to feel tired. Our efficiency of performed activities will also decrease, which will make us less efficient regardless of whether the work is mental or physical. That is why it is so important to ensure adequate parameters of the air in the room and try to keep them at an appropriate, as far as possible unchanging level. Despite many years of research on this topic, many questions still remain unanswered.

Thermal comfort is the state of human satisfaction with the conditions of the room in which they stay. Our body does not feel cold or too warm then. In general, a person's feeling of thermal comfort has a significant impact on the efficiency of their work. Failure to ensure appropriate air parameters may lead to a reduction in the effectiveness of the activities performed. The main parameters influencing the determination of thermal comfort are air temperature and velocity, relative humidity, average radiation temperature and physical activity. Air temperature is the main factor affecting thermal comfort. It's too high or too low value causes that a person does not feel comfortable in a given room. The human body can function in a very wide temperature range, but only to a small extent it feels thermal comfort. The most popular method to determine thermal comfort is the Fanger model [1]. This model was developed in the 1970s by O. Fanger and is the basis of the applicable standards: ISO 7730 [2] together with PN-EN 16798-1: 2019 [3]. The Fanger model is related to the following two indicators: PMV, defined as the Predicted Mean Vote, and PPD, which is the Predicted Percentage of Dissatisfied people. The PMV index is expressed using a seven-point scale according to the American standard ASHRAE 55 [4], which is on a scale from -3 to +3 , where negative means cold and positive means hot. According to the Fanger model, for the thermal environment to be acceptable for most buildings, the PMV value must be between -0.5 and 0.5 for most buildings. It is assumed that humans prefer a neutral thermal environment, i.e., a PMV value of zero, as a comfortable thermal environment.

The Fanger model practically comes down to the PMV index, which is expressed by the following equation according to [2]:

$$
\begin{gathered}
P M V=[0.303 \cdot \exp (-0.036 \cdot M)+0.028] \cdot \\
\left\{(M-W)-3.05 \cdot 10^{-3} \cdot[5733-6.99 \cdot(M-W)-\right. \\
\left.p_{a}\right]-0.42 \cdot[(M-W)-58.15]-1.7 \cdot 10^{-5} \cdot M \cdot \\
\left(5867-p_{a}\right)-0.0014 \cdot M \cdot\left(34-t_{a}\right)-3.96 \cdot 10^{-8} \\
f_{c l} \cdot\left[\left(t_{c l}+273\right)^{4}-\left(\bar{t}_{r}+273\right)^{4}\right]-f_{c l} \cdot h_{c} \cdot\left(t_{c l}-\right. \\
\left.\left.t_{a}\right)\right\}
\end{gathered}
$$

where: $\mathrm{M}$ - metabolic rate $\left[\mathrm{W} / \mathrm{m}^{2}\right], \mathrm{W}$ - effective mechanical power $\left[\mathrm{W} / \mathrm{m}^{2}\right], \mathrm{I}_{\mathrm{cl}}$ - thermal insulation of clothing $\left[\mathrm{m}^{2} \mathrm{~K} / \mathrm{W}\right], \mathrm{t}_{\mathrm{a}}$ - air temperature $\left[{ }^{\circ} \mathrm{C}\right], \bar{t}_{r^{-}}$average

* Corresponding author: nkrawczyk@tu.kielce.pl 
radiation temperature $\left[{ }^{\circ} \mathrm{C}\right], \mathrm{p}_{\mathrm{a}}$ - partial pressure of water vapour $[\mathrm{Pa}], \mathrm{t}_{\mathrm{cl}}$ - surface temperature of clothing $\left[{ }^{\circ} \mathrm{C}\right]$. Over the past few years, many scientists have studied the difference between thermal sensations and PMV. Aghniaey et al. [5,6] conducted research on thermal comfort on a university campus in the United States. The study measured the following parameters: temperature and air velocity, relative humidity, $\mathrm{CO}_{2}$ concentration, and average radiation temperature. The results showed that the respondents preferred higher temperature ranges, especially women accept a warmer environment. Majewski et al. [7] conducted research in an intelligent building and noticed differences between the actual and forecast values of thermal comfort. Broday et al. [8] analysed thermal comfort by comparing Fanger's model with people's real thermal sensations. The authors [9] used a thirteen-degree scale of thermal comfort for the thermal comfort tests instead of the seven-level scale used according to ISO 7730 [2]. They found that the thermal sensations of the respondents were satisfactory in the range of -0.5 to +0.5 . Almeida et al. [10] conducted studies in school buildings where they examined the relationship between PMV and Mean Thermal Sensation (MTS) and operating temperature. They concluded that there was a significant relationship between them. The article [11] presents the Fanger model for air-conditioned office buildings and presents the differences between the model and survey results. Djamila [12] analysed the influence of individual microclimate elements on thermal comfort. Jazizadeh et al. [13] conducted research in office buildings in terms of thermal comfort. They concluded that the most important factor influencing thermal comfort is air temperature. Mors et al. [14] conducted research in school buildings and observed a significant difference between the PMV determined by the standard and the survey data. Luo et al. [15] determined that thermal comfort was significantly influenced by an increase in the metabolic rate. The research presented by Vilcekova et al. [16] showed a discrepancy between the results of PMV calculations and the actual sensations. The results also showed an increase in $\mathrm{CO}_{2}$ concentration during school classes. Enescu [17] presents models and indicators for thermal sensation and shows that validation of thermoregulation models is difficult, which contributes to increased interest. The latest research is improving the models. In Poland, studies on thermal comfort and indoor air quality were conducted, among others, by Dudkiewicz et al. [18], Majewski et al. [7], Piotrowski et al. [19].

The article analyses the thermal comfort in an intelligent building together with the feelings of the people examined. Two indicators PMV and PPD were taken into account and a modification of the PMV equation was proposed based on preliminary test results. The motivation behind the paper is the fact that many studies found in literature report that there are differences between the actual thermal sensations of people and the Fanger model and still this issue is not solved.

\section{Material and method}

The research was conducted in the autumn of 2020 in the intelligent building "Energis" of the Kielce University of Technology. Figure 1 below presents a photo of the building from the Western side.

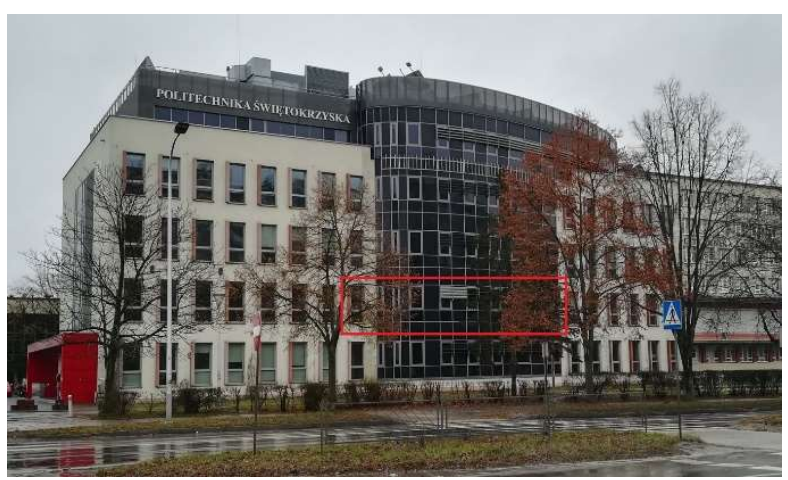

Figure 1. Photo of the "Energis" building.

The study was conducted in a lecture hall on the first floor with mechanical ventilation (marked in red in the figure). The intelligent Energis building has been designed to provide adequate air parameters for its occupants. Air-conditioning and heating devices significantly affect the conditions in the room, therefore the designed air-conditioning and heating systems should ensure appropriate parameters, depending on the purpose of the room. The next figure shows the room where tests were done (with thermal images generated by an infrared camera - Fig. 2).

a)
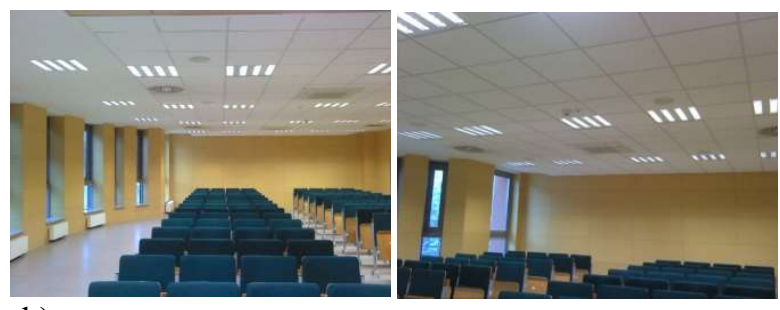

b)

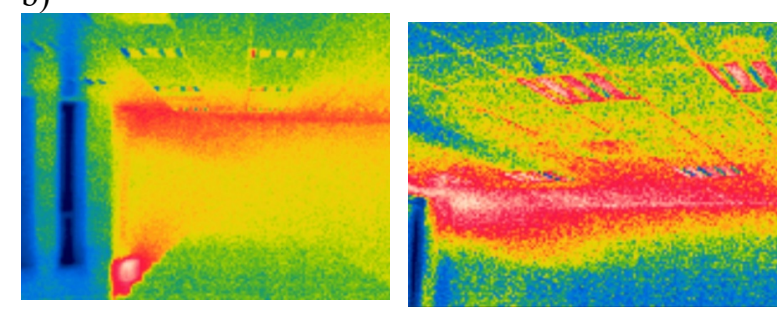

Figure 2. Lecture room no 1.14: a) photos, b) thermal images.

As can be seen in the above figures the thermal insulation of the exterior walls of the building is fine. There are no thermal bridges or other sources of heat losses. The interior wall seems to have elevated temperature, but it might be caused by the presence of other sources of heat such as building installations located there.

The research was carried out using two methods, by filling in questionnaires by students and measuring air 
parameters in the rooms. A microclimate meter was used to determine the air parameters. The probes were placed at the height of the respondents, at the level of the thermal centre of gravity. Parameters such as temperature and air velocity, relative humidity, carbon dioxide concentration and light intensity were measured. The measurement accuracy of the measured parameters are as follows: for the indoor air temperature it is $+/-0.3{ }^{\circ} \mathrm{C}$, air flow velocity: $+/-0.03 \mathrm{~m} / \mathrm{s}$, relative humidity: $+/-2 \%$ and concentration of $\mathrm{CO}_{2}:+/-50 \mathrm{ppm}$. Local comfort issues such as Draught Rate or Turbulence Intensity were not taken into account in the surveys conducted due to their marginal impact in this kind of building (the velocity was quite uniform in the area where the students were). The graph below shows how carbon dioxide changes over time. It was considered sufficient due to the fact that the value stabilised (changes did not exceed the accuracy of $\mathrm{CO}_{2}$ detection).

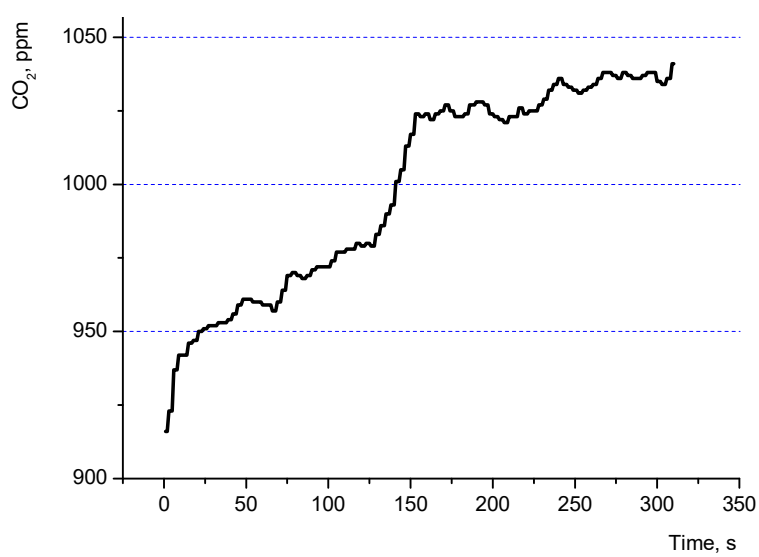

Figure 3. Graph of carbon dioxide changes over time.

From the graph, it can be concluded that carbon dioxide increases with time. During the increase in carbon dioxide, students sit in the test room. The greatest increase can be seen after about 160 seconds. After this time, the curve continues to rise, but not so sharply. The concentration of carbon dioxide in a room depends on the number of people staying in it. The more people in the room, the faster the carbon dioxide amount curve will rise. In the tested room, the concentration of carbon dioxide did not exceed the permissible concentration of about $5000 \mathrm{ppm}$ [20] (the threshold of $5000 \mathrm{ppm}$ is actually quite high comparing to the values in air quality standards), because the classroom has a large area. With higher carbon dioxide, a person feels discomfort. During the stabilization of the air parameters, the participants completed questionnaires concerning the feeling of thermal sensations in the room. Below is a picture of the microclimate meter that was used to measure air parameters and the students completing the questionnaires (Figure 4).

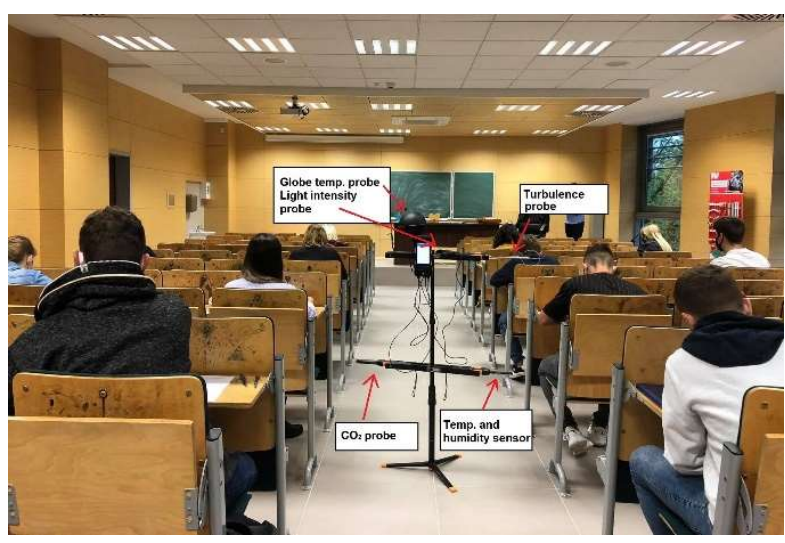

Figure 4. Photograph of the measuring device Testo 400 with probes.

\section{Results and discussion}

The research was conducted in the fall with 54 participants, 15 women and 39 men aged 18 to 21 years. The experimental programme involved questions on thermal sensations, acceptability, preferences and others, however on Figure 5 only the frequency of answers about the thermal sensations votes (TSV) in the rooms studied has been given. This parameter defines how individual people assess their thermal environment.

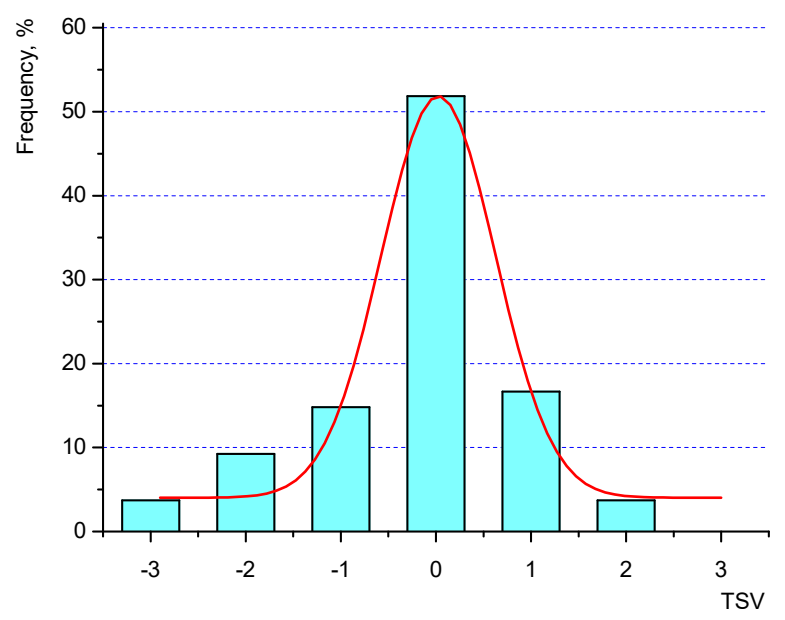

Figure 5. The frequency of the answers on thermal sensations votes: "-3" - too cold, "-2" - too cool, "-1" - pleasantly cool, "0" - comfortable, "1" - pleasantly warm, "2" - too warm, "3" - too hot.

The conducted research shows that the "too cold" option was $3.7 \%$, i.e., 2 people out of 54 people chose this answer. The answer "too warm" was repeated as much as "too cold". The respondents answered "too cool" 5 times, which is $9.26 \%$. The answer "pleasantly cool" was selected 8 times, i.e., the frequency was $14.81 \%$. The most frequently given answer was the "comfortable" option. It constitutes $51.85 \%$ of all questionnaires completed by the respondents. In the case of the "pleasantly warm" answer, its frequency was $16.67 \%$. There is also a Gaussian curve in the graph that represents the distribution of the normal. Comparing the results of the conducted research, it can be concluded that the students did not feel well in the room under 
study. This means that there was no thermal comfort because the percentage of selecting "too cold", "too warm", "too warm" and "too hot" was greater than $10 \%$. It amounted to $16.67 \%$, which is how many people were dissatisfied with the prevailing conditions. Figure 6 shows the frequency of answers about the air quality in the rooms studied has been given.

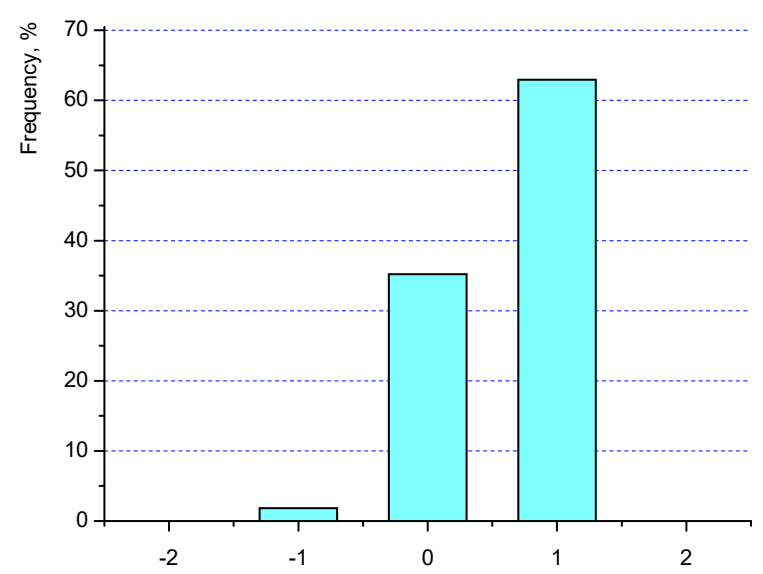

Figure 6. The frequency of answers given by the respondents regarding air quality: "-2" - very bad, "- 1 " - bad, " 0 " - neither good nor bad, "1" - good, "2" - very good.

The conducted research on air quality assessment shows that the most common answer given by the respondents was the answer "good" and it amounted to $62.96 \%$, which corresponds to 34 responses out of 54 . The second largest number of answers selected is the option "neither good nor bad". It repeated 19 times, i.e., its frequency is $35.19 \%$. The "bad" option is $1.85 \%$. During the research, at the end of the questionnaire, the respondents completed a with information on the subject's sex, age, height and weight. This was used to calculate the BMI (body mass index) and compared it to the thermal voices of the volunteers (Figure 7). Body mass index is a ratio of mass (in ' $\mathrm{kg}$ ') over height (in ' $m$ ') to the second order.

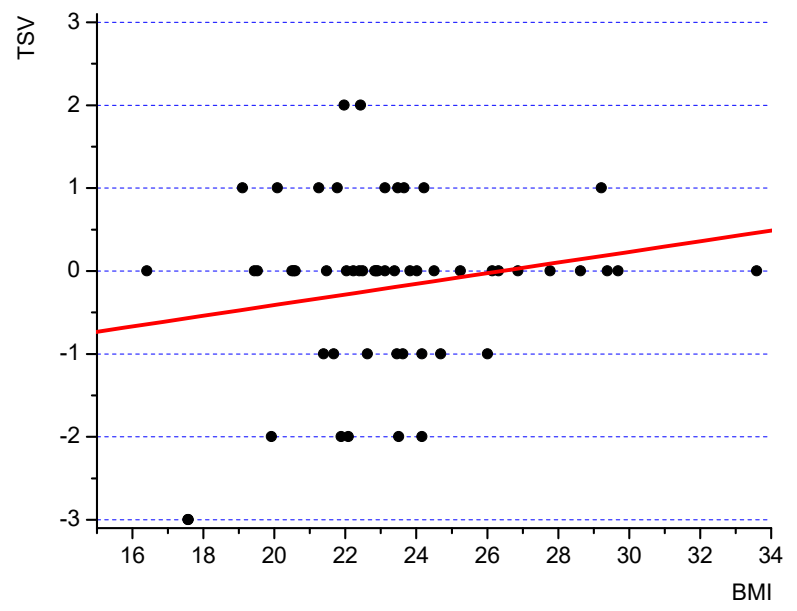

Figure 7. Dependence of TSV on the BMI mass index.

Based on the results, it can be concluded that people with BMI in the range of less than 20 rate their thermal sensation vote as cold, while with an index between 22 and 26 they feel comfortable. The study shows that the higher the BMI range, the higher the thermal sensation vote. Consequently, people with higher BMI tend to prefer lower temperature, with lower BMI the opposite is true. Below in Figure 8 is a graph showing the respondents' thermal sensations vote (TSV) and thermal preferences vote (TPV) - which describes the preferences of people on the temperature value in the room.

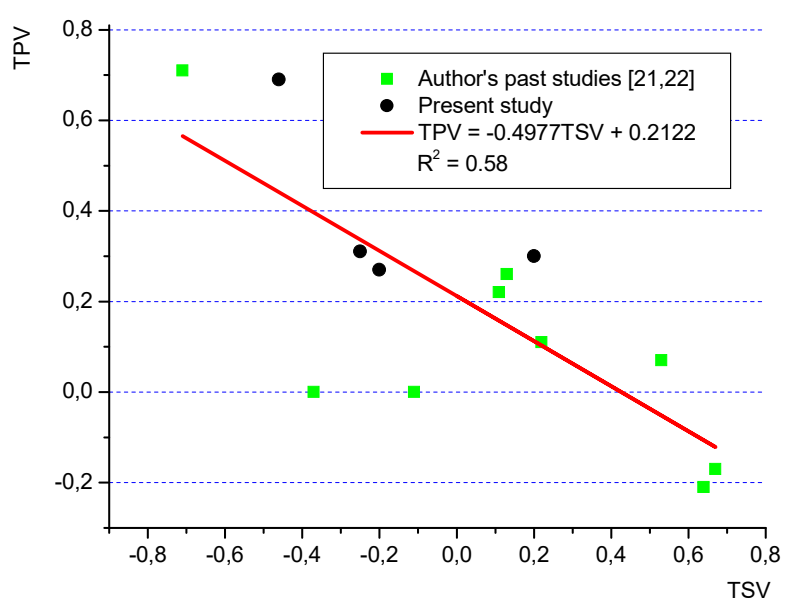

Figure 8. Thermal sensations vote (TSV) and thermal preferences vote (TPV) of the respondents.

The graph shows the thermal impressions and thermal preferences of the respondents. Average TSV and TPV scores were calculated for each room. From the above graph, it can be seen that those who felt comfortable $(\mathrm{TSV}=0$ ) would like the room to be no changed (TPV $=0)$. When comparing the distribution of scores based on thermal sensation vote (TSV) and thermal preference vote (TPV), it can be observed that most of the subjects preferred the conditions they were in. Overall, during the study, students rated their thermal environment as warm, while their thermal preferences varied. During the tests, the concentration of carbon dioxide was also determined. Figure 9 shows the air temperature and the concentration of carbon dioxide in the lecture room as well as other rooms tested earlier by the author and considered for the model modification (similar number of people - students were present in those rooms).

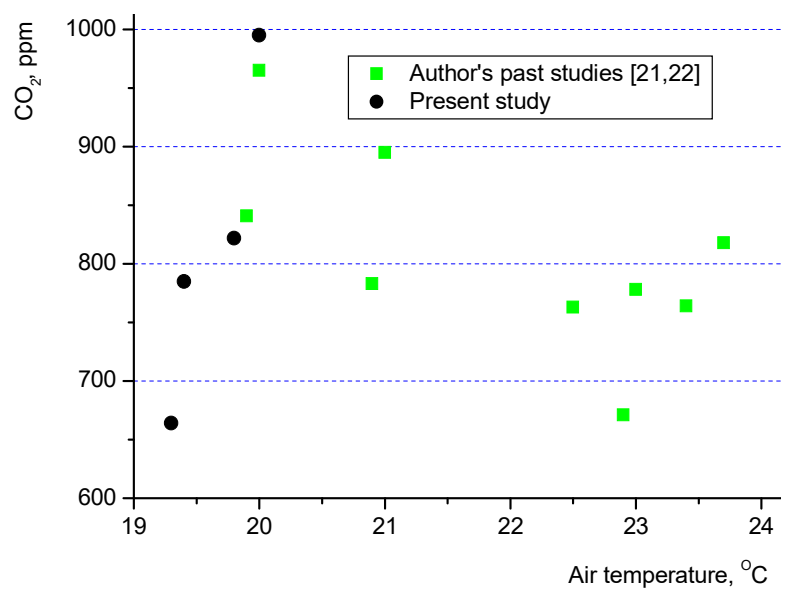


Figure 9. Air temperature and $\mathrm{CO}_{2}$ concentration in rooms.

The figure above shows the indoor temperature and carbon dioxide data. The research results were based on the results from the literature $[21,22]$ and the results from the autumn 2020 period. Carbon dioxide has a significant impact on air quality; therefore, this phenomenon requires further research. However, it needs to be reported that the data indicate a relatively low level of $\mathrm{CO}_{2}$ in the studied educational rooms.

Based on the experimental data of questionnaires and direct measurements, the Fanger model was modified considering the impact on carbon dioxide, as shown in formula (2) below:

$$
\begin{gathered}
P M V=[0.303 \cdot \exp (-0.036 \cdot M)+0.028] \cdot \\
(-0.00015) \cdot C O_{2} \cdot\left\{(M-W)-3.05 \cdot 10^{-3} \cdot\right. \\
{\left[5733-6.99 \cdot(M-W)-p_{a}\right]-0.42 \cdot[(M-W)-} \\
58.15]-1.7 \cdot 10^{-5} \cdot M \cdot\left(5867-p_{a}\right)-0.0014 \cdot M \cdot \\
\left(34-t_{a}\right)-3.96 \cdot 10^{-8} \cdot f_{c l} \cdot\left[\left(t_{c l}+273\right)^{4}-\right. \\
\left.\left.\left(\bar{t}_{r}+273\right)^{4}\right]-f_{c l} \cdot h_{c} \cdot\left(t_{c l}-t_{a}\right)\right\}
\end{gathered}
$$

Equation (2) was extended by the product $(-0.00015)$. $\mathrm{CO}_{2}$, which "brought" the results from the research closer to the trend line. The next figure shows the results of PMV and TSV and after model modification.

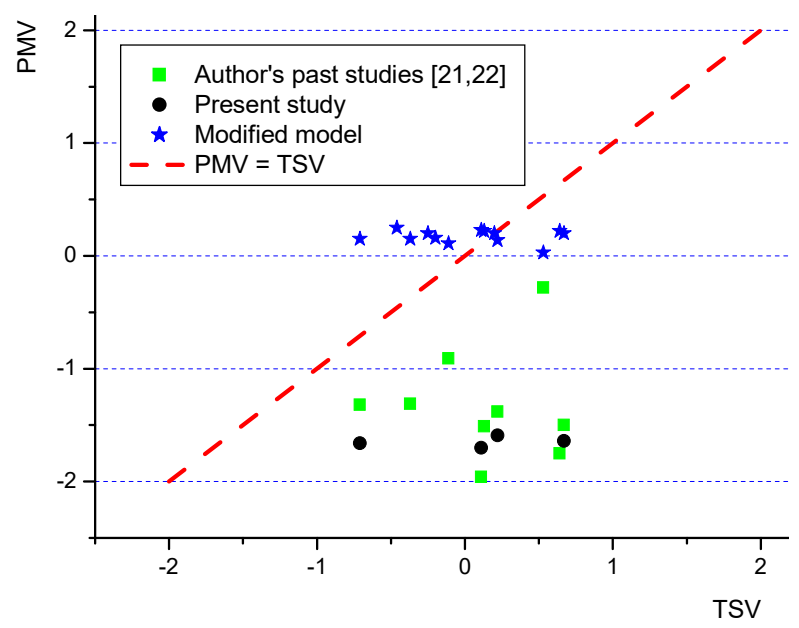

Figure 10. Modification of the Fanger model.

The above graph represents a modification of the Fanger model including the impact of carbon dioxide. Green points mark the results of measurements from previous tests [21,22]. Black points are the current research (from surveys and calculations according to Fanger's formula), while blue points are the results after model modification. The red trend line indicates $100 \%$ compliance with the model. One may notice that the results marked in blue are closer to the trendline than the rest of the results. The chart shows a significant improvement when modifying the formula.

Another index is PPD. Its comparison from the questionnaires and model calculation results indicates significance differences, as shown below (Fig. 11).

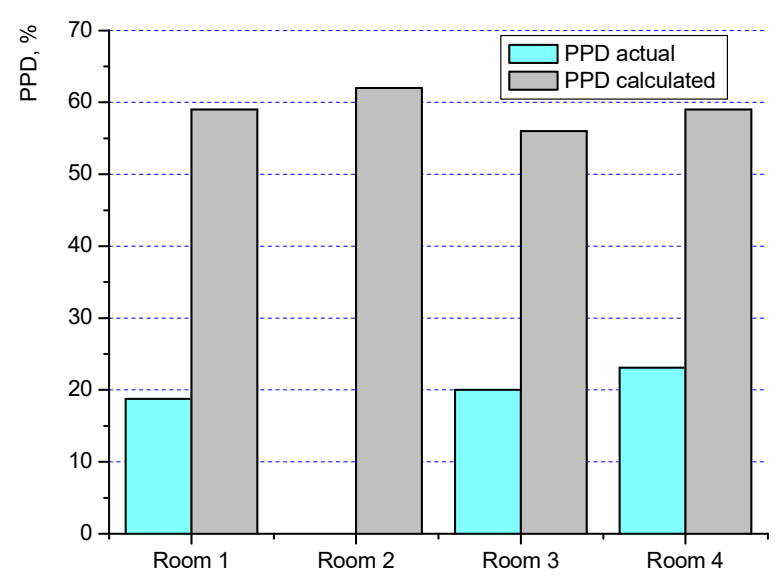

Figure 11. Comparison of actual test results and calculations according to the Fanger model for PPD.

On the basis of the presented figure, it can be seen that the values of the predicted percentage of dissatisfied people do not coincide with the Fanger model. The standard [3] stipulates that the percentage of people dissatisfied with the microclimate should not exceed $10 \%$ for these types of buildings. It can be concluded that this value has not been met in an intelligent building Energis, where tests were conducted.

\section{Conclusions}

The research carried out in an intelligent building showed that the number of people dissatisfied with the prevailing conditions exceeded $10 \%$. Most people prefer a warmer environment, so this could explain the number of dissatisfied people. When analysing the Fanger model, it can be seen that it differs from the responses of people participating in the study regarding thermal comfort. The current model provides a comfortable temperature, which is actually too high for the respondents. Modification of the model taking into account the influence of carbon dioxide concentration on thermal comfort resulted in the results of the surveys being consistent with the ideal model (TSV $\cong \mathrm{PMV}$ ). When assessing the predicted number of dissatisfied people (PPD), it can also be noticed that the results of the respondents do not coincide with the Fanger's model. Further work should therefore be done on this topic to create an even more accurate model, especially that the number of test rooms was quite limited. The study is a preliminary study and currently, due to the pandemic situation, the number of research results is limited, but it will be expended.

\section{Acknowledgements}

The project is supported by the program of the Minister of Science and Higher Education under the name: "Regional Initiative of Excellence" in 2019-2022 project number 025 / RID / 2018/19 financing amount PLN 12,000,000. 


\section{References:}

[1] P.O. Fanger, Komfort cieplny, tł. doc. dr inż. K. Kostyrko, dr A. Kostryko, Arkady, Warszawa 1974.

[2] ISO International Organisation for Standardization, Ergonomics of the thermal environment - Analytical determination and interpretation of thermal comfort using calculation of the PMV and PPD indices and local thermal comfort criteria, International Standard ISO 7730, 2005.

[3] PN-EN 16798-1:2019, Energy Performance of Buildings-Ventilation for Buildings-Part 1: Indoor Environmental Input Parameters for Design and Assessment of Energy Performance of Buildings Addressing Indoor Air Quality, Thermal Environment, Lighting and Acustics.

[4] ASHRAE Standard 55-2017, Thermal Environmental Conditions for Human Occupancy.

[5] S. Aghniaey, M. L, Thomas, T.N. Sharpton, S.P. Douglass, T. Oliver, M. Sutter, Thermal comfort evaluation in campus classrooms during room temperature adjustment corresponding to demand response, $\mathrm{BaE}, 148$, pp. 488-497, 2019.

[6] S. Aghniaey, T.M. Lawrence, Cooling season demand response and the real world, ASHRAE J. 59, 4, pp. 68-70, 2017.

[7] G. Majewski, Ł.J. Orman, M. Telejko, N. Radek, J. Pietraszek, A. Dudek, Assessment of thermal comfort in the intelligent buildings in view of providing high quality indoor environment, Energies, 13(8), 1973, 2020.

[8] E.E. Broday, J.A. Moret, A.A. de Paula Xavier, R. de Oliveira, The approximation between thermal sensation votes (TSV) and predicted mean vote (PMV): A comparative analysis, International Journal of Industrial Ergonomics, 69, pp. 1-8, 2019.

[9] P. Ricciardi, C. Buratti, Environmental quality of university classrooms: Subjective and objective evaluation of the thermal, acoustic, and lighting comfort conditions, $\mathrm{BaE}, 127$, pp. 23-36, 2018.

[10] R.M.S.F. Almeida, N.M.M. Ramos, V.P. de Freitas, Thermal comfort models and pupils' perception in free-running school buildings of a mild climate country, EaB 111, pp. 64-75, 2016.

[11] S. Manu, Y. Shukla, R. Rawal, L.E. Thomas, R. de Dear, Field study of thermal comfort cross multiple climate Jones for the subcontinent: IMAC, BaE, 98, pp. 55-70, 2016.

[12] H. Djamila, Indoor thermal comfort predictions: Selected issues and trends, RaSER, 74, pp. 569-580, 2017.

[13] F. Jazizadeh, F.M. Marin, B. Becerik-Gerber, A thermal preference scale for personalized comfort profile identification via participatory sensing, BaE, 68, pp. 1440-149, 2013.

[14] S.T. Mors, J.L.M. Hensen, M.G.L.C. Loomans, A.C. Boerstra, Adaptive thermal comfort in primary school classrooms: Creating and validating PMV-based comfort charts, BaE, 46, pp. 2454-2461, 2011.

[15] M. Luo, X. Zhou, Y. Zhu, J. Sundell, Revisiting an overlooked parameter in thermal comfort studies, the metabolic rate, EaB, 118, pp. 152-159, 2016.

[16] S. Vilcekova, L. Meciarova, E.K. Burdova, J. Katunska, D. Kosicanova, S. Doroudiani, Indoor environmental quality of classrooms and occupants' comfort in a special education school in Slovak Republic, BaE, 120, 29-40, 2017.

[17] D. Enescu, Models and Indicators to Assess Thermal Sensation Under Steady-State and Transient Conditions, Energies, 12, 841, 2019.

[18] E. Dudkiewicz, J. Jeżowiecki, Dyskomfort lokalny na stanowisku pracy, Rocznik Ochrony Środowiska, 11, 751-759, 2009.

[19] J.Zb. Piotrowski, Ł.J. Orman, X. Lucas, E. Zender - Świercz, M. Telejko, D. Koruba, Tests of thermal resistance of simulated walls with the reflective insulation, Proc. of Int. Conf. "Experimental Fluid Mechanics 2013", Czech Republic, EPJ Web of Conferences, 67, 02095, 2014.

[20] Regulation of the Minister of Family, Labour and Social Policy of 12th June 2018 on the Maximum Admissible Concentrations and Intensities of Harmful to Health Agents in the Working Environment (Dz. U. No 1286)

[21] N. Krawczyk, Z. Piasta, Preliminary test results of thermal comfort in a classroom, SaE, 11 (4), pp. 281-286, 2019.

[22] N. Krawczyk, A. Kapjor; A study of thermal comfort at Kielce University of Technology, SaE, 12 (3), pp. 127-132, 2020. 